Tertiary beds of the Mississippi embayment and the gravels within the Missouri valleys, I shall not attempt to consider, as they should be seen on the ground before being discussed. As far as presented, they do not overcome the various lines of evidence which point to changes in the level of Misouri since its Paleozoic emergence; the last of these changes being the one in consequence of which the present valleys were cut in the denuded surface of the region.

W. M. DAvis.

Harvard College, Oct. $3^{\mathrm{r}}$, 1893 .

\section{COON CATS}

SeErng Mr. J. N. Baskett's note on page 220 of the current volume of Science, concerning coon cats, I venture to inform you that I was struck with the extraordinary appearance of one of these cats owned by Mr. Will Carleton, who had it with him in the Catskill Mountains the present summer. I asked him about the cat and he told me the same fable which Mr. Baskett relates, but he went on to say that of course the story was incorrect and that in his opinion this peculiar race of cats from Maine is descended from some Perisian or Angora breed brought down to Maine by early French settlers from Canada. I believe that this was surnise on Mr. Carleton's part, but it seemed reasonable to me and if you receive no more satisfactory explanation in reply to Mr. Baskett's question, you are at liberty to use this.

\section{O. Howard.}

Washington, D. C., November 9

$$
\text { PUMP WATER. }
$$

IN America we often observe that the farmer, in his efforts to economize the steps of the housewife, digs his domestic well in close vicinity of his drains and outbuildings, but I have yet to see at home so pronounced a case of unsanitary surroundings as I observed in Germany a short time ago.
The top of a tall wooden pump, which crowned the family well, just peeped out from a huge manure heap which completely surrounded it. So large was the heap that the pump handle had to be operated by a rope, and the water was carried beyond the heap by a small trough.

Rome, Italy, Nov. 2 WM. P. MASON.

COON-CATS.

IN answer to Mr. J. N. Baskett's question regarding "Coon-Cats" in your issue of Oct. 20, 1893, I would say that this cross-breed of animals has been known for many years, more particularly in the State of Maine. The error attributing these mongrels to a cross between our domestic feline, and the raccoon, Procyon lotor, is as general as it is ridiculous; for it stands to reason that animals of different families could not interbreed. The notion is about as ridiculnus as a provasent story among the ignorant that (cat) owls bear their young alive.

The subject of "coon-cats," or sometimes called mulecats, has been repeatedly discussed in many papers, and it is now generally conceded that this hybrid is the result of an alliance of our domestic tabby with some Oriental feline-probably the Angora. This cross would show the long, bushy tail of the Oriental species. But Mr. Baskett is in error in supposing these animals plantigrade, and if he secures a skull, which he can easily do, he will find that the dentition is pronouncedly feline.

These cats are quite common in parts of New England, and may be purchased at a very reasonable figure, and according to the demands and the supply in the cat market. Few persons are able to distinguish between genuine Angoras and these hybrids, and many are the unsuspecting buyers who have paid a high price for a common "coon-cat" worth not more than two dollars.

Moris GibBs.

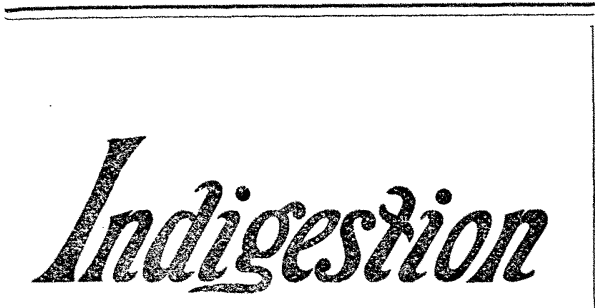

Horsford's Acid Phosphate

Is the most effective and agreeable remedy in existence for preventing indigestion, and relieving those diseases arising from a disordered stomach.

Dr. W. Gardner, Springfield, Mass., says, "I value it as an excellent preventative of indigestion, and a pleasant acidulated drink when properly diluted with water, and sweetened."

Descriptive pamphlet free on application to Rumford Chemical Works, Providence, $R$ Beware of Substitutes and Imitations.

For sale by all Druggists.

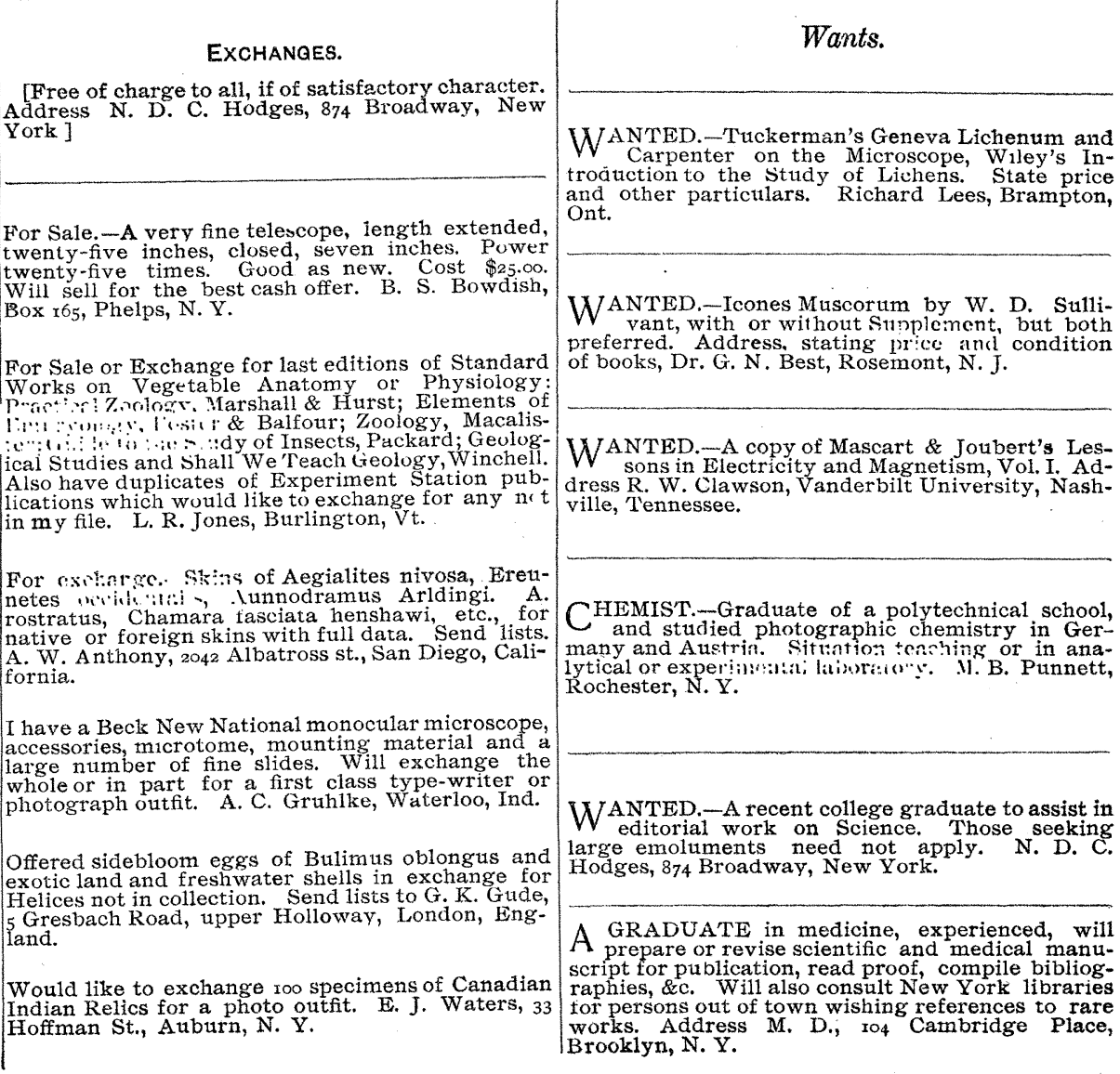

